\title{
PAPERS
}

\section{Predictive factors for regression of gastric MALT lymphoma after anti-Helicobacter pylori treatment}

\author{
A Ruskoné-Fourmestraux, A Lavergne, P H Aegerter, F Megraud, L Palazzo, A de \\ Mascarel, T Molina, J-C L Rambaud, the Groupe d'Etude des Lymphomes Digestifs \\ (GELD)
}

\begin{abstract}
Department of Gastroenterology, Hôtel-Dieu, AP-HP, Paris, France A RuskonéFourmestraux L Palazzo
\end{abstract}

Hôpital Lariboisière, Paris, France J-C L Rambaud

Department of Pathology, Hôpital Lariboisière, AP-HP, Paris, France A Lavergne

Hôtel Dieu, AP-HP, Paris, France T Molina

Department of Biostatistics, Hôpital Ambroise Paré, Boulogne, France P H Aegerter

Department of Pathology, University of Bordeaux, France A de Mascarel

Department of Bacteriology, University of Bordeaux, France F Megraud

Fondation Française de Cancérologie Digestive, Dijon, France

Groupe d'Étude des Lymphomes Digestifs (GELD)†

†Participants of GELD are detailed in the appendix.

Correspondence to: Dr A Ruskoné-

Fourmestraux, Service de Gastro-entérologie, Hôtel-Dieu, 1 place du Parvis Notre Dame, 75181 Paris Cedex 04, France. agnes.fourmestraux@ htd.ap-hop-paris.fr

\begin{abstract}
Background and aims-Discrepant remission rates $(41-100 \%)$ have been reported for patients with localised low grade gastric mucosa associated lymphoid tissue (MALT) lymphoma after eradication of Helicobacter pylori. The aim of this study was to explain these discrepancies and to determine the predictive factors of gastric lymphoma regression after antiH pylori treatment.
\end{abstract}

Patients and methods-Forty six consecutive patients with localised gastric MALT lymphoma (Ann Arbor stages $\mathrm{I}_{\mathrm{E}}$ and $\mathrm{II}_{\mathrm{E}}$ ) were prospectively enrolled. All had gastric endoscopic ultrasonography and $H$ pylori status assessment (histology, culture, polymerase chain reaction, and serology). After anti-H pylori treatment, patients were re-examined every four months.

Results-Histological regression of the lymphoma was complete in 19/44 patients (43\%) (two lost to follow up). Median follow up time for these 19 responders was 35 months (range 10-47). No regression was noted in the $10 \mathrm{H}$ pylori negative patients. Among the $34 \mathrm{H}$ pylori positive patients, the $H$ pylori eradication rate was $100 \%$; complete regression rate of the lymphoma increased from $56 \%(19 / 34)$ to $79 \%(19 / 24)$ when there was no nodal involvement at endoscopic ultrasonography. There was a significant difference between the response of the lymphoma restricted to the mucosa and other more deep seated lesions $(p<0.006)$. However, using multivariate analysis, the only predictive factor of regression was the absence of nodal involvement $(p<0.0001)$. Conclusion-In $\boldsymbol{H}$ pylori positive patients with localised gastric MALT lymphoma, carefully evaluated and treated without any lymph node involvement assessed by endoscopic ultrasonography, complete remission of lymphoma was reached in $79 \%$ of cases.

(Gut 2001;48:297-303)

Keywords: mucosa associated lymphoid tissue; gastric lymphoma; Helicobacter pylori
Gastric low grade B cell lymphomas arising from mucosa associated lymphoid tissue (MALT) are the most frequent lymphomas among those located in the primary digestive tract. ${ }^{1}$ There is now evidence supporting the role of Helicobacter pylori infection in the development of these gastric lymphomas (GLs). Indeed, $H$ pylori provides the antigenic stimulus which is mediated by mucosal $\mathrm{T}$ cells for sustaining growth of gastric MALT lymphoma. ${ }^{1}$ Since the first cases of GL regression after such eradication were reported in $1993,{ }^{23}$ various remission rates of $41-100 \%$ have been published for several low grade GL series. ${ }^{4-11}$ These variations may be due to the heterogeneity of these series, particularly as regards clinical presentation and tumour characteristics. In fact, data are sometimes lacking concerning $H$ pylori infection status and/or tumour extension and stage. The aim of this prospective study was therefore to determine, in consecutive patients with precise inclusion criteria, the effect of eradication of $H$ pylori infection on low grade localised MALT GL, and to define the predictive factors of lymphoma regression.

\section{Patients and methods}

From June 1995 to July 1998, consecutive patients with localised low grade MALT GLs were prospectively enrolled in a multicentre study by the French Groupe d'Etude des Lymphomes Digestifs (GELD). Informed consent was obtained from all patients and the study was approved by the local ethics scientific committee.

PATIENTS AND INCLUSION CRITERIA

Patients suspected of having a histological diagnosis of low grade GL on the basis of routine endoscopic biopsies were asked to participate in the study. A second gastroscopy allowed the biopsy of 8-10 tissue specimens which were placed in neutral buffered formalin and Bouin's fluid or frozen before $H$ pylori treatment. The diagnosis of GL was confirmed by a

Abbreviations used in this paper: MALT, mucosa associated lymphoid tissue; GL, gastric lymphoma; EUS, endoscopic ultrasonography; CT, computed tomography; PCR, polymerase chain reaction. 
review committee of eight pathologists, according to Isaacson's criteria and Wotherspoon's scoring system, ${ }^{12}$ and post-treatment biopsies were examined by the same panel of pathologists (see appendix for list of pathologists). Besides the centrocyte-like cell infiltrate, lymphoepithelial lesions were required to confirm the diagnosis of GL (score 5). H pylori was systematically looked for using the Giemsa stain. Immunohistochemical analyses were performed on all paraffin embedded biopsies, and included a search with anti-CD20, anti-CD3, and anticytokeratin antibodies to confirm the $\mathrm{B}$ cell nature of the lymphoid infiltrate and visualise lymphoepithelial lesions. Detection of B cell monoclonality by polymerase chain reaction (PCR) amplification of rearranged immunoglobulin heavy chains was performed on all lesioned tissue specimens. ${ }^{12}$

Four other biopsies were obtained separately from the gastric antrum and corpus for assessment of $H$ pylori status by histology, tissue culture, and PCR, together with blood sampling for $H$ pylori serology. ${ }^{13}$ Histological specimens were stained with haematoxylin eosin and Giemsa.

For culture, tissue biopsies were grounded, plated on three media (two selective and one non-selective), and incubated in a microaerobic atmosphere at $37^{\circ} \mathrm{C}$ for $7-10$ days. H pylori was identified on the basis of positive oxidase, catalase, and urease tests. Susceptibility to clarithromycin and metronidazole was studied using the $\mathrm{E}$ test and by absence of growth on an agar containing $8 \mathrm{mg} / \mathrm{l}$ of that compound, respectively. For PCR, primers on the urease gene were used and amplified products were detected on agarose gels. ${ }^{13}$ IgG specific for $H$ pylori were tested using the Pyloriset-EIA-G kit (Orion Diagnostica, Espoo, Finland) and immunoblotting was performed with the Helicoblot 2.0 kit (Genelabs, Geneva, Switzerland). CagA status, which was detected by immunoblotting analysis of the patient's sera, was determined from the presence of a $120-130 \mathrm{kDa}$ band. Both kits were used according to the manufacturer's recommendations.

Extension of the disease was defined according to the Ann Arbor staging system, modified by Musshoff: staging procedures included recording of the patient's physical examination, ileocolonoscopy together with upper gastrointestinal tract endoscopy, small bowel and chest radiography, abdominal computed tomography (CT scan), Waldeyer's ring examination with endoscopy and biopsies or CT scan, and bone marrow biopsy. Gastric endoscopic ultrasonography (EUS) was always performed initially and after treatment, by experienced investigators and the data reviewed by the referring endoscopist (LP). The depth of infiltration was evaluated as previously described. ${ }^{14}$ Lymph nodes detected around the duodenum and stomach were considered as infiltrated by lymphoma at EUS if they were spherical, hypoechogenic, and $1 \mathrm{~cm}$ or more in diameter. The echo endoscopists were blinded as to the detailed results of histology, and the patholo- gists were blinded to the results of EUS staging.

Final inclusion criteria were as follows: histologically proved low grade MALT GL (score 5) with a localised tumour at stage $\mathrm{I}_{\mathrm{E}}$ (parietal involvement) or $\mathrm{II}_{\mathrm{E} 1}$ (contiguous nodal involvement) based on abdominal CT scan. Consecutive patients were included, whether or not histological studies showed the presence of $\mathrm{H}$ pylori.

\section{STUDY DESIGN}

After inclusion, each patient was investigated during follow up by the same practitioner and endoscopist. During follow up, endoscopic biopsies were performed as initially, in the area of suspected lymphoma and for $H$ pylori detection.

On day 0 , all patients started the same anti- $H$ pylori treatment for 14 days: $40 \mathrm{mg}$ lansoprazole twice daily, $1 \mathrm{~g}$ amoxicillin twice daily, and $500 \mathrm{mg}$ clarithromycin twice daily. ${ }^{15}{ }^{16}$ Compliance was assessed by counting unused medication. The first endoscopic follow up examination was performed 30 days after the end of treatment to check both the effectiveness of $H$ pylori eradication, as assessed by histology, tissue culture, and PCR, and the absence of macroscopic tumour progression. Those patients with persistent $H$ pylor $i$ were tested for susceptibility to metronidazole and given a second line treatment. ${ }^{15}$ Thereafter, patients were followed up by clinical evaluation, upper endoscopy with multiple biopsies for histology, bacteriology and molecular study, and EUS every four months during the first year, and every six months thereafter.

$H$ pylori eradication (responder) was considered successful if there was regression of the initial endoscopic lesion and the histological lymphoid infiltrate. Histological regression of the lymphoid infiltrate was diagnosed when a score of 0-3 was observed, based on the score proposed by Wotherspoon et al. This indicated that there was no evident remnant of atypical lymphoid cells. When a lymphomatous infiltrate remained according to this score (score 5), even without lymphoepithelial lesions (score 4), the patient was not considered to be in remission. For all patients, lymphoma regression was checked by at least three series of follow up examinations. Patients with persistence of the initial macroscopic lesions, such as ulcer at four months, or progression or recurrence of the initial tumour pattern at control endoscopy, or patients whose histological remission was not complete after 12 months, were considered failures in terms of medical treatment. Patients who did not respond to eradication of $H$ pylori were referred for total gastrectomy or radiation therapy when surgery was inadvisable or declined by the patient.

\section{EVALUATION OF RELATED FACTORS OF} LYMPHOMA REGRESSION

Factors considered for evaluation were: (1) clinical features such as age and sex; (2) endoscopic features; (3) presence of $H$ pylori infection, according to the results of histology, tissue culture, PCR, serology, and CagA status; 
Table 1 Presentation at diagnosis of low grade localised gastric mucosa associated lymphoid tissue (MALT) lymphomas according to their Helicobacter pylori status and relationship between clinical and gastric endoscopic ultrasonography (EUS) features and outcome after anti-H pylori eradication, for 19 patients who experienced complete macroscopic and histological remission (responders) and 15 who did not (non-responders). No H pylori negative patient had regression of lymphoma after anti-H pylori treatment.

\begin{tabular}{|c|c|c|c|c|c|c|}
\hline & \multicolumn{5}{|c|}{ H pylori positive patients* } & \multirow[b]{2}{*}{$\begin{array}{l}\text { H pylori negative } \\
\text { patients }\end{array}$} \\
\hline & $\begin{array}{l}\text { All } \mathrm{H}_{p+}+ \\
\text { patients }\end{array}$ & Responders & Non-responders & $\begin{array}{l}\text { Bivariate } \\
\text { analysis } p \neq\end{array}$ & $\begin{array}{l}\text { Multivariate } \\
\text { analysis } p\end{array}$ & \\
\hline No of cases & 34 & $19(56 \%)$ & 15 & & & 10 \\
\hline Age (y) (mean, range) & $56(21-76)$ & $54(21-76)$ & $59(43-73)$ & $0.007 \dagger$ & NS & $60(43-76)$ \\
\hline $\operatorname{Sex}(M / F)$ & $22 / 12$ & $10 / 9$ & $12 / 3$ & 0.10 & NS & $7 / 3$ \\
\hline \multicolumn{7}{|l|}{$\begin{array}{l}\text { Endoscopy: main } \\
\text { features }(n)\end{array}$} \\
\hline Ulcer & 25 & 14 & 11 & NS & NS & 6 \\
\hline Erosions & 3 & 1 & 2 & NS & NS & 3 \\
\hline Erythema & 4 & 3 & 1 & NS & NS & 0 \\
\hline Thick folds or tumour & 7 & 2 & 5 & 0.10 & NS & 2 \\
\hline \multicolumn{7}{|l|}{ EUS (n): layer } \\
\hline $\begin{array}{c}\text { infiltrated to: } \\
\leqslant \text { Mucosa }\end{array}$ & 18 & 14 & 4 & $<0.006+t$ & NS & 2 \\
\hline Submucosa & 7 & 3 & 4 & & & 2 \\
\hline Muscularis propria & 5 & 1 & 4 & & & 3 \\
\hline Serosa & 4 & 1 & 3 & & & 3 \\
\hline Nodal involvement & 10 & 0 & 10 & $<0.0001$ & 0.0001 & 5 \\
\hline Adjacent organ & 0 & 0 & 0 & & & 0 \\
\hline $\begin{array}{l}\text { Depth of infiltration } \\
\quad(\mathrm{mm})(\text { mean }(\mathrm{SD}))\end{array}$ & $7.6(5.2)$ & $5.9(2.6)$ & $9.8(6.9)$ & 0.005 & NS & $11.1(5.1)$ \\
\hline \multicolumn{7}{|l|}{ Stage (Ann Arbor) } \\
\hline $\mathrm{I}_{\mathrm{E}}(\mathrm{n})$ & 24 & $19(79 \%)$ & 5 & & & 6 \\
\hline $\mathrm{II}_{\mathrm{E}}(\mathrm{n})$ & 10 & 0 & 10 & & & 4 \\
\hline
\end{tabular}

$\mathrm{n}$, number of patients; *at least one positive test: histology or serology.

$\ddagger$ Relation to outcome (bivariate analysis, $\chi^{2}$ test for nominal variables, Mann-Whitney test for ordinal or continuous variables); $\dagger$ log age was tested; ††layer infiltrated, mucosa $v$ beyond.

and (4) EUS features - that is, depth of tumour infiltration and nodal or adjacent organ involvement.

Studies on monoclonality of lymphomas did not affect either the evaluation of the results or therapeutic strategy.

\section{STATISTICAL ANALYSIS}

For comparison of responders to treatment versus non-responders by bivariate analysis, the $\chi^{2}$ test was used for categorical variables, and continuous or ordinal variables were compared using the non-parametric MannWhitney test. Variables related to response with a $\mathrm{p}$ value less than 0.2 were introduced into a logistic regression model. Backward and forward stepwise procedures were performed and interaction terms were also tested. ${ }^{17} \mathrm{~A} \mathrm{p}$ value of less than 0.01 was considered statistically significant in the final analysis.

\section{Results}

INITIAL PRESENTATION

Of the 70 consecutive patients initially enrolled in the study, six refused to give informed consent to participate, two had associated Waldeyer's ring lymphoma after staging, and 14 were considered diagnostic errors after the pathologists' reviews of their cases. Six of 14 had $H$ pylori gastritis and eight had high grade MALT lymphoma. Of the remaining 48 patients included in the series, two were lost to follow up two and six months after diagnosis. Two other patients were withdrawn from the study because their $H$ pylori status could not be assessed (negative histology and serology not tested). Thus 44 localised low grade GLs in 29 men and 15 women were finally evaluated in 17 different centres. Mean age was 56 years (median 58 (range 21-76)). All 44 patients were symptomatic at presentation. Most endoscopic lesions were ulcers $(n=31)$, erythema $(n=4)$, sometimes with erosions $(n=6)$, and thick folds or tumours $(n=9)$. Initial clinical staging with CT scan revealed 35 stage $\mathrm{I}_{\mathrm{E}}$ cases and nine stage $\mathrm{II}_{\mathrm{E} 1}$ cases. EUS displayed a normal appearance or thickening confined to the mucosa in 20 cases, invasion of the submucosa in nine cases, of the muscularis propria in eight, and of the serosa in seven. In addition, suspicious enlarged paragastric lymph nodes were detected by EUS in 15 of these 44 patients, hence revealing with this technique 15 stage $\mathrm{II}_{\mathrm{E} 1}$ cases. PCR disclosed a monoclonal band in 34/41 (83\%) patients.

$H$ pylori infection was detected by histology and serology in 32 (73\% of 44 tested) and 30 (70\% of 43 tested) patients, respectively, while PCR and tissue culture were positive in only 15 (40\%) and $14(38 \%)$ of 38 and 37 tested cases, respectively. None of the patients with negative results for histology or serology was positive for tissue culture or PCR. Serology by ELISA and immunoblotting gave the same results. Two patients with negative histology had positive serology and conversely two with positive histology had negative serology. H pylori status was thus assessed in 44 cases by a positive result for histology and/or serology: 34 cases $(77 \%)$ were considered $H$ pylori positive. Sixteen of these 34 cases were colonised by CagA positive strains. Clinical, endoscopic, and EUS features at presentation according to $H$ pylori status are reported in table 1 . There was no significant difference in the initial presentation or local staging according to $H$ pylori status of patients. 


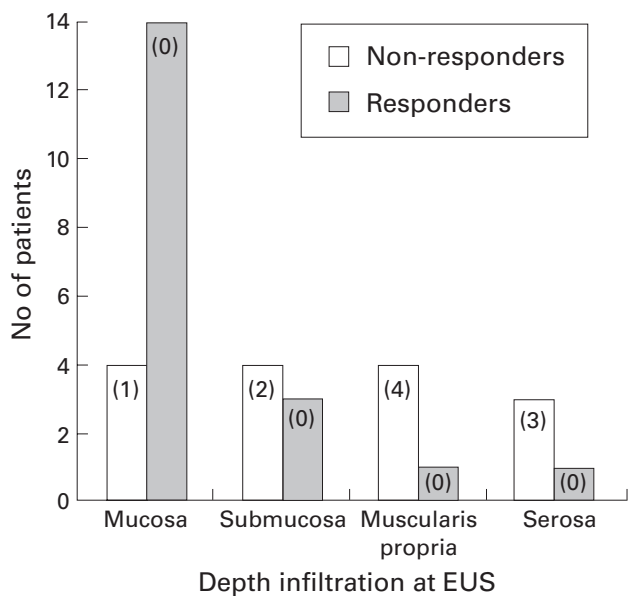

Figure 1 Thirty four cases of low grade gastric mucosa associated lymphoid tissue lymphoma with Helicobacter pylori infection: relation between features of endoscopic ultrasonography (EUS) and tumour response after H pylori eradication. Values in parentheses indicate number of patients with nodal involvement at EUS.

OUTCOME

Table 1 shows clinical, endoscopic, and EUS data for the 44 patients in relation to $H$ pylori status and outcome. $H$ pylori infection was eradicated after the first line treatment in 29 patients (91\% of $34 \mathrm{H}$ pylori positive patients). Because of resistance to clarithromycin in three patients, strains were eradicated by second line treatment.

Histological complete regression of the lymphoma was observed in 19 of 44 patients (43\%). All responders were $H$ pylori positive by our criteria and no response was observed in the $10 \mathrm{H}$ pylori negative patients. Hence 19 of 34 H pylori positive patients (56\%; 95\% confidence interval 39-72\%) achieved complete regression of the lymphoma (responders) (table 1). Median follow up from day 0 for the 19 responders was 35 months (range 10-47). Median time required to achieve complete histological remission after anti- $H$ pylori treatment was six months (mean eight months; range 2-18). For one patient, we allowed a longer period of observation and follow up was prolonged to 18 months after complete disappearance of the macroscopic lesion at gastric endoscopy and EUS with noticeable regression of lymphomatous infiltrate on histology at 12 months. The median follow up period with continuous complete remission was 23 months (range 8-44). Two relapses were observed during follow up after 12 and 43 months, respectively, but there was no evidence of $H$ pylori reinfection. In eight responders, a monoclonal band was still detectable when their response was evaluated at the time of response evaluation.

Of the 25 patients who failed to achieve complete remission, 22 underwent surgery and three radiation therapy, and the median follow up period was eight months (range 2-21). The characteristics of their unresponsive GLs were persistence of the macroscopic lesion on endoscopy in six cases, bleeding lesions in three, and incomplete histological regression at 12 months in 16 . In one patient with a large initial tumour, a surgical specimen revealed a high grade component lymphoma.

PREDICTIVE FACTORS OF OUTCOME

We focused our evaluation of predictive factors of lymphoma regression on the $H$ pylori positive group. A marked male predominance was observed in the non-responder group whose mean age was significantly more advanced than that of the responders. Of the 16 patients colonised by CagA positive strains, eight were responders and eight were nonresponders. For endoscopic features, there was no difference between the two groups. Table 1 shows the relation between features of pretreatment EUS and the response of the lymphoma to treatment. The absence of lymphoma regression was related to depth of parietal infiltration $(p<0.005)$, with a better chance of GL regression when EUS was normal or showed only mucosal involvement (fig 1). The response rate was therefore highest for the mucosa $(78 \%$ of cases) and then decreased markedly to $43 \%$, $20 \%$, and $25 \%$ for the submucosa, muscularis propria, and serosa, respectively. There was a significant difference between the response rates of GLs restricted to the mucosa and other more deep seated GLs $(p<0.006)$. The frequency of nodal involvement increased with depth of infiltration. However, in three nonresponders, nodal involvement at EUS was observed whereas there was limited parietal infiltration. When nodal involvement was observed by EUS, no response was noted. The remission rate for the 24 patients without any nodal enlargement at EUS was 79\% (95\% confidence interval 63-95\%).

In the multivariate analysis of these 34 patients, the only remaining predictive factor of complete lymphoma regression was absence of nodal involvement at EUS ( $\mathrm{p}<0.0001)$.

\section{Discussion}

To our knowledge, our prospective study, together with that of Steinbach et al, are the only attempts at combined analysis in consecutive patients of the clinical, endoscopic, bacteriological, and histological features which may affect complete regression of low grade MALT GL after $H$ pylori eradication. ${ }^{11}$ In the literature, tumour regression after eradication of $H$ pylori with a similar median follow up varied markedly from $41 \%$ to $100 \%$ (table 2 ). ${ }^{4-11}$ In the present study, complete regression of histological lesions was obtained in $43 \%$ of cases and concerned all localised tumours in stages $\mathrm{I}_{\mathrm{E}}$ and $\mathrm{II}_{\mathrm{E} 1}$, whatever their $H$ pylori status.

The apparent discrepancies between remission rates in these different series may be due to the heterogeneity of the GLs selected. In relation to this, five main factors should be considered: (1) histological criteria for diagnosis; (2) $H$ pylori status; (3) demographic features; (4) initial clinical stage of tumour and modality of its evaluation; and (5) follow up of patients.

HISTOLOGICAL CRITERIA FOR DIAGNOSIS

Histologically, it may be difficult to distinguish between the florid reactive lymphoid infiltrate 
Table 2 Summary of available data in the literature on gastric low grade mucosa associated lymphoid tissue (MALT) lymphoma series (H pylori positive patients) and their outcome after H pylori eradication

\begin{tabular}{|c|c|c|c|c|c|c|c|c|c|}
\hline Reference & Year & $n$ & $\begin{array}{l}\text { Initial } \\
\text { stage }^{\star}\end{array}$ & $\begin{array}{l}\text { Local staging } \\
\text { procedures }\end{array}$ & $\begin{array}{l}\text { Initial } \\
\text { histological } \\
\text { score }^{\star \star}\end{array}$ & $\begin{array}{l}\text { Time to achieve } \\
\text { remission (months) } \\
\text { (median (range)) }\end{array}$ & $\begin{array}{l}\text { Complete } \\
\text { remission rate } \\
\%(n)\end{array}$ & $\begin{array}{l}\text { Period of follow up after } \\
\text { remission (months) } \\
\text { (median (range)) }\end{array}$ & Relapses ( $n$ ) \\
\hline Savio et al ${ }^{6}$ & 1996 & 12 & $\mathrm{I}_{\mathrm{E}}$ & CT & $4-5$ & $3(2-4)$ & $84(11)$ & $24(14-36)$ & 0 \\
\hline Neubauer et $a l^{7 \text { a }}$ & 1997 & 50 & $\mathrm{I}_{\mathrm{E}}$ & CT \pm EUS & 5 & $4(0.5-8.5)$ & $80(40)$ & $15(0-40)$ & 5 \\
\hline Pinotti et al ${ }^{9 \mathrm{~b}}$ & 1997 & 45 & $\mathrm{I}_{\mathrm{E}}$ & $\mathrm{CT}$ & 5 & $5(3-18)$ & $68(30)$ & $23(2-66)$ & 2 \\
\hline Montalban et al ${ }^{8}$ & 1997 & 9 & $I_{E}$ & CT & 5 & $7(5-7))$ & $88(8)$ & $14(7-22)$ & $?$ \\
\hline Nobre Leitao et al ${ }^{10}$ & 1998 & 17 & $\mathrm{I}_{\mathrm{E}}^{\mathrm{E}}$ & CT+EUS & $4-5$ & $2(1-12)$ & $100(17)$ & $12(2-39)$ & 1 \\
\hline Steinbach et al ${ }^{11}$ & 1999 & $\begin{array}{l}28 \\
23\end{array}$ & $\frac{\mathrm{I}_{\mathrm{E}}}{\mathrm{I}_{\mathrm{E}}}+\mathrm{II}_{\mathrm{E}}$ & CT or EUS & 5 & $(3-45)$ & $\begin{array}{l}50(14) \\
56(13)\end{array}$ & $(>18)$ & 0 \\
\hline Present study & 2000 & $\begin{array}{l}34 \\
24\end{array}$ & $\begin{array}{l}\mathrm{I}_{\mathrm{E}}+\mathrm{II}_{\mathrm{E} 1} \\
\mathrm{I}_{\mathrm{E}}\end{array}$ & $\mathrm{CT}+\mathrm{EUS}$ & 5 & $6(2-18)$ & $\begin{array}{l}56(19) \\
79(19)\end{array}$ & $23(8-44)$ & 2 \\
\hline
\end{tabular}

${ }^{\text {a }}$ Follow up study by Bayerdörffer et al 1995: 33 cases reported. ${ }^{4}$

${ }^{\text {b}}$ Follow up study by Roggero et al $1995 .{ }^{5}$

$\mathrm{n}$, number of cases; CT, abdominal computed tomography; EUS, gastric echographic ultrasonography.

${ }^{\star}$ Ann Arbor staging system; ${ }^{\star \star}$ histological score by Wotherspoon $e t$ al. ${ }^{2}$

of $H$ pylori gastritis and the infiltrate characterising low grade MALT GL, as shown here in the six patients with $H$ pylori gastritis who were erroneously thought to have GL. The morphological hallmark of MALT GL is proliferation of centrocytic-like cells and epithelial destruction that causes lymphoepithelial lesions detected on histological examination. ${ }^{126}$ These criteria were defined by Isaacson, ${ }^{1}$ and according to the score of Wotherspoon and colleagues, ${ }^{2}$ only score 5 tumours can be considered as confirmation of the diagnosis. Inclusion of score 4 GL (4, strongly suspected lymphoma on the basis of dense lymphoid infiltrate) may have contributed to the higher response rates of $84 \%$ and $100 \%$ of some studies. ${ }^{10}$ Savio et al also suggested that the large number of endoscopies performed with systematic biopsies in their institution together with minimal endoscopic abnormalities might account for their earlier detection of the disease and therefore the higher percentage of responses obtained. In the present study, monoclonal proliferation was detected in $38 / 46$ GLs (that is, $83 \%$ ), a rate similar to those reported in the literature. ${ }^{718}$

Conversely, accurate histological grading, especially recognition of relevant high grade components, is sometimes difficult, ${ }^{19}$ as shown in the present study in which eight cases of high grade lymphoma were initially enrolled but were not included after review by the committee of pathologists. The results of the German studies also illustrate this difficulty ${ }^{4}$ : among their non-responders who were referred for surgery, histological analysis of surgical specimens revealed high grade lymphomas in deeper layers than the mucosa, and it is recognised that high grade lymphomas do not generally respond to $H$ pylori eradication. ${ }^{20}$ It could be argued that the higher rate of failure in our study was due to the presence of an underlying high grade component. In fact, only one of our gastrectomy specimens exhibited both low and high grade components. The only patient with a high grade component had a large ulcerated tumour at endoscopy with extensive layer infiltration at EUS. We agree with Taal and colleagues ${ }^{21}$ that such transformation must be suspected when the endoscopic lesion has the features of a large GL, and when EUS indicates the corresponding pattern of the tumoral infiltration. Moreover, in the present study, the initial endoscopic features were not predictive of the response after anti- $H$ pylori treatment. However, Steinbach et al reported a more favourable response of tumours of the distal stomach compared with tumours of the proximal stomach. ${ }^{11}$ Finally, our experience indicates that as long as a sufficient number of biopsy specimens (at least 10 according to our standardised protocol) are taken and are reviewed by experienced pathologists, the possibility of a high grade lymphoma can be virtually ruled out.

\section{H PYLORI STATUS}

In the present study, the hallmark of $H$ pylori infection was not only the presence of bacteria on histological preparations but also positive serology, which proved effective and must therefore be considered. Indeed, in this study, one of the responders had positive serology but no $H$ pylori on histological samples, probably because they had already been given antibiotics or were receiving antisecretory therapy for ulceration at the time of lymphoma diagnosis. As a result, the final proportion of low grade GL patients with a $H$ pylori infection was $77 \%$ (34 of 44 tested). As in most previous studies of low grade GL, we did not find any relationship between CagA positive $H$ pylori strains and the lymphoma. Moreover, no significant association was found between the presence of CagA positive $H$ pylori strains and outcome of GL. The absence of lymphoma regression in our 10 $H$ pylori negative patients $(40 \%$ of all nonresponders) is indirect evidence of the accuracy of histology and serology for determination of $H$ pylori status.

Our non-responders included all 10 who were $H$ pylori negative. Similar results were reported in the series of Steinbach et al for six $H$ pylori negative patients. ${ }^{11}$ These cases may have been associated with other types of GLs not linked to $H$ pylori infection, or to more advanced tumours. Other gastric Helicobacter may have been involved but not detected by the methods used. However, the absence of regression of these tumours after antibiotic treatment argues against this hypothesis. The results of Nakamura et al suggested that the presence of $H$ pylori in biopsy samples was likely to be associated with early stage GL. ${ }^{22}$ It is interesting that in the latter study, non- 
responders were older than responders. When a careful search is made for $H$ pylori infection, a negative result could avoid not only a useless eradication procedure but also a prolonged follow up. However, the absence of $H$ pylori on histological gastric biopsies does not necessarily imply the absence of recent $H$ pylori infection. Therefore, in clinical practice we strongly recommend serological testing in the event of negative histology.

\section{DEMOGRAPHIC FEATURES}

Patients responding to treatment were statistically younger than non-responders. Nonresponders were predominantly male. We found no data in the literature concerning these points except that in nodal nonHodgkin's lymphoma, male sex is associated with a worse prognosis.

INITIAL STAGE OF THE TUMOUR

The initial stage of the tumour may also affect the results of treatment. Here, some of the non-responders probably had more advanced lesions. Indeed, in our study, remission increased from $56 \%$ to $79 \%$ when only the $24 \mathrm{H}$ pylori positive patients with stage $\mathrm{I}_{\mathrm{E}}$ GLs were considered. These results are comparable with the $80 \%$ regression rate obtained by Neubauer and colleagues. ${ }^{7}$ In both series, the score required for inclusion was 5 in patients with stage $I_{E} G L$, as evaluated by initial histology, and clinical staging evaluated by EUS (present study) or CT scan. ${ }^{7}$ However, we cannot explain the lower rate of complete remission $(56 \%)$ obtained by Steinbach et al in their stage $\mathrm{I}_{\mathrm{E}}$ patients assessed by either EUS or CT scan. Nobre Leitao et al, who obtained a regression rate of $100 \%$, selected their patients using CT scan together with gastric EUS. ${ }^{10}$ They argued that non-responders in other series may initially have had more advanced lesions than those reported with possible nodal involvement, and that EUS had not been systematically included in the management of these patients. ${ }^{9}$ In the present study, EUS was performed in all cases, and was also much more sensitive than CT scan. The fact that most of the 15 patients with stage $\mathrm{II}_{\mathrm{E} 1} \mathrm{GL}$ underwent gastrectomy prompted us to verify that EUS had good sensitivity in detecting lymph node involvement. Its value for such detection was also demonstrated in our previous study. ${ }^{14}$

Discrepancies between different response rates may be due not only to nodal involvement but also to the depth of wall invasion. Eidt et al demonstrated that the probability of lymph node infiltration increased when it was correlated with the depth of gastric wall infiltration. ${ }^{23}$ It is interesting to note that in the present study, one of the GLs with invasion restricted to the mucosa had nodal involvement (fig 1). The predictive role of EUS has only been studied in two series of 22 and 17 patients with MALT GL who were given anti- $H$ pylori treatment. ${ }^{10}{ }^{24}$ Complete regression of MALT lymphoma was significant and mainly observed when the GL did not infiltrate deeper than the mucosa ${ }^{10}$ or submucosa. ${ }^{24}$ In our experience, only patients with tumour invasion restricted to

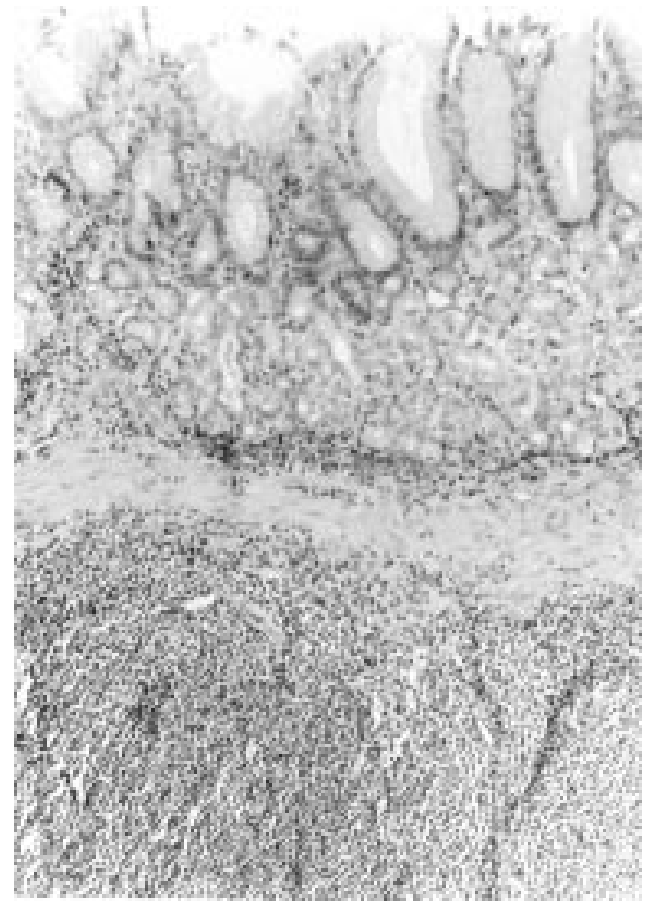

Figure 2 Surgical specimen of a low grade gastric mucosa associated lymphoid tissue lymphoma which did not regress after eradication of Helicobacter pylori. Histological examination of the lesion revealed a deep neoplastic lymphomatous infiltrate in the submucosa, but the mucosa was free of tumour. This could explain possible sampling error bias as falsely negative biopsy findings at endoscopic control. Haematoxylin-eosin stain $\times 350$.

the mucosa had a significant probability of regression ( $78 \%$ of our cases). If the submucosa and deeper layers are involved, the GL is less likely to regress after $H$ pylori eradication. The high rate of response in other published series probably corresponds to early GL with a limited depth of gastric wall infiltration, but this has not always been evaluated. ${ }^{46-810}$

FOLLOW UP OF RESPONDERS

Among the 34 patients who were $H$ pylori positive, complete histological lymphoma regression was noted in 19 cases (56\%) after a median period of six months, which is similar to that reported elsewhere (table 2). It is interesting to note that in our experience, as in others, complete responses may only occur after 18 months of follow up. In most series, as in the present one, the median period of observed continuous complete remission was about two years. Here, among the GLs which regressed, we noted persistent clones in eight tumours which could suggest a greater probability of relapse of GL, but this has not yet been proved. ${ }^{7}$ In fact, Isaacson et al recently reported that in their responders, the monoclonal B cell population could still be present after six years of follow up without any evidence of histological disease. ${ }^{25}$ In the present study, two relapses were observed at 12 and 43 months. Such late relapses have also been reported in other series, only one with $H$ pylori reinfection, but must be distinguished from an occult residual disease. To prevent this possible sampling error bias as falsely negative biopsy findings, especially when the endoscopic pat- 
tern is almost normal after medical treatment (fig 2), it is worth confirming remission of GL in at least three controls at intervals of four months during the first year of follow up.

\section{Conclusion}

This study showed that $56 \%$ of localised low grade MALT GLs in $H$ pylori positive patients achieved complete remission at 6-18 months after eradication of $H$ pylori. In such patients, $H$ pylori infection was accurately assessed by gastric histology and serology. None of our $H$ pylori negative GLs (23\% of all cases) regressed. This makes systematic eradication of the bacteria, irrespective of $H$ pylori status, of doubtful significance. In carefully selected $H$ pylori positive patients without any lymph node involvement assessed by EUS, complete remission was achieved in $79 \%$ of cases. EUS proved more sensitive than endoscopy or CT scan for accurate staging, which was then crucial for predicting tumour response to bacterial eradication. Lymph node involvement, even when paragastric, and/or tumour penetration beyond the submucosa, were indications of little or no response. The persistence of an abnormal $\mathrm{B}$ cell clone after $H$ pylori eradication did not appear to affect the prognosis, but longer follow up studies are needed to confirm this.

Part of this work was presented at the 1997 Annual Meeting of the American Gastroenterological Association in Washington and published in abstract form (Gastroenterology 1997;112:A648)

Supported by grants from the Délégation à la Recherche Clinique, Assistance Publique-Hôpitaux de Paris (AP-HP).

\section{Appendix}

Data for the study were contributed by the following participants of the Groupe d'Etude des Lymphomes Digestifs (GELD). S Charpin (Argenteuil), R Collet (Boulogne s/mer), AM Justum (Caen), R Marti (Calais), S Mathieu, C Boni (Clermont-Ferrand), L Bedenne, AL Villing (Dijon), P Delasalle (Grasse), A Boruchowicz , Y Touze, JF Colombel (Lille), J Lartigues, M Le Rhun (Nantes), JL Legoux (Orléans), G Amouyal, E Abdini, Y Bouhnik, M Charbit, J Fourmestraux, JD Grangé, C Matuchansky, S Oudard, R Parc, M Salmeron, D Seguenot, K Vahedi (Paris), C Eugène, $\mathrm{P}$ Rocher, RL Vitte (Poissy), $\mathrm{O}$ Bouché, H Louvet, P Zeitoun (Reims), P Novello (St-Denis), M Escartin (St Jean de Luz), E Graf (St-Nazaire), Th Morin, A Glibert (Tarbes), JF Bouret (Vannes), F Jean (Versailles), M Ducreux (Villejuif).

Review committee of pathologists. J Audouin, F Berger, F Charlotte, MC Copin, A Lavergne, A de Mascarel, Y Selves, L Xerri. We thank M Sisnaki for his technical assistance.

\footnotetext{
1 Isaacson PG. Gastrointestinal lymphoma. Hum Pathol
} 1994;25:1020-29.
2 Wotherspoon AC, Doglioni C, Diss TC, et al. Regression of primary low-grade B-cell lymphoma of mucosa-associated primary low-grade B-cell lymphoma of mucosa-associated lymphoid tissue type after

3 Stolte M, Eide S. Healing gastric MALT lymphomas by eradicating $H$. pylori? Lancet 1993;342:568

4 Bayerdörffer E, Neubauer A, Rudolph B, et al. Lymphoma Study Group: regression of primary gastric lymphoma of mucosa-associated lymphoid tissue type after cure of Helicobacter pylori infection. Lancet 1995;345:1591-94.

5 Roggero E, Zucca E, Pinotti G, et al. Eradication of Helicobacter pylori infection in primary low-grade gastric lymphoma of mucosa-associated lymphoid tissue. Ann Intern Med 1995;122:767-69.

6 Savio A, Franzin G, Wotherspoon AC, et al. Diagnosis and post-treatment follow-up of Helicobacter pylori positive gastric lymphoma of mucosa-associated lymphoid tissue: histology, polymerase chain reaction, or both? Blood 1996; 87:1255-60.

7 Neubauer A, Thiede C, Morgner A, et al. Cure of Helicobacter pylori infection and duration of remission of lymphoma. I Natl Cancer Inst 1997;89:1350-55.

lymphoma. I Natl Cancer Inst 1997;89:1350-55.
8 Montalban C, Manzanal A, Boixeda D, et al. Helicobacter

8 Montalban C, Manzanal A, Boixeda $\mathrm{D}$, et al. Helicobacter pylori eradication for the treatment of low-grade gastric
MALT lymphoma: follow-up together with sequential MALT lymphoma: follow-up together with sequent
molecular studies. Ann Oncol 1997;8(suppl 2):37-40.

9 Pinotti G, Zucca E, Roggero E, et al. Clinical features, treatment and outcome in a series of 93 patients with low-grade gastric MALT lymphoma. Leukemia Lymphoma 1997;26: 527-37.

10 Nobre-Leitao C, Lage P, Cravo M, et al. Treatment of gastric MALT lymphoma by Helicobacter pylori eradication: a study controlled by endoscopic ultrasonography. $A m \mathcal{F}$ Gastroenterol 1998;93:732-36.

11 Steinbach G, Ford R, Glober G, et al. Antibiotic treatment of gastric lymphoma of mucosa-associated lymphoid tissue. Ann Intern Med 1999;131:88-95

12 de Mascarel A, Dubus P, Belleannée G, et al. Low prevalence of monoclonal B cells in Helicobacter pylori gasprevalence of monoclonal B cells in Helicobacter pylori gas-
tritis patients with duodenal ulcer. Hum Pathol 1998;29: tritis patien

13 Megraud F. How should Helicobacter.pylori infection be diagnosed? Gastroenterology 1997;133:93-98

14 Palazzo L, Roseau G, Ruskoné-Fourmestraux A, et al. Endoscopic ultrasonography in the local staging of primary gastric lymphoma. Endoscopy 1993;25:502-8.

15 Megraud F. Epidemiology and mechanism of antibiotic resistance in Helicobacter pylori. Gastroenterology 1998;115: 1278-82.

16 Lindt T, Megraud F, Unge P, et al. The MACH2 study: role of omeprazole in eradication of Helicobacter pylori. Gastroenterology 1999;116:248-53.

17 Harrell FE, Plee KL, Mark DB. Multivariate prognostic models: issues in developing models, evaluating assumptions and adequacy, and measuring reducing errors. Stat Med 1996;15:361-87.

18 Rudolph B, Bayerdorffer E, Ritter M, et al. Is the polymerase chain reaction or cure of Helicobacter pylori infection of help in the differential diagnosis of early gastric mucosaassociated lymphatic tissue lymphoma? F Clin Oncol 1997; 15:1104-9.

19 De Jong D, Boot H, Van Heerde P, et al. Histological grading in gastric lymphoma: pretreatment criteria and clinical relevance. Gastroenterology 1997;112:1466-74.

20 Boot H, de Jong D, Van Heerde P, et al. Role of Helicobacter pylori eradication in high-grade MALT lymphoma. Lancet 1995;346:448-9.

21 Taal BG, Boot $\mathrm{H}$, Van Heerde $\mathrm{P}$, et al. Primary non-Hodgkin lymphoma of the stomach: endoscopic pattern and prognosis in low versus high-grade malignancy in relation to the MALT concept. Gut 1996;39:556-61.

22 Nakamura S, Yao T, Aoyagi K, et al. Helicobacter pylori and primary gastric lymphoma. Cancer 1997;79:3-11.

23 Eidt S, Stolte M, Fisher R. Factors influencing lymph node infiltration in primary malignant lymphoma of the mucosainfiltration in primary malignant lymphoma of the mucosa-
associated lymphoid tissue. Pathol Res Pract 1994;190: associated

24 Sackman M, Morgner A, Rudolph B, et al. Regression of primary gastric low-grade MALT lymphoma after cure of Helicobacter pylori infection is predicted by endosonographic staging. Gastroenterology 1997;113:1087-90.

25 Isaacson PG, Diss T, Wotherspoon A et al. Long term follow-up of gastric MALT lymphoma treated by eradication of $H$. pylori with antibiotics. Lancet 1999;117,750-51. 